\title{
Accumulation small hydro power plant on lake - Slovenian case
}

\author{
L. Somi ${ }^{1}$, K. Deželak ${ }^{1}$, G. Štumberger ${ }^{1}$ \\ ${ }^{1}$ Power Laboratory Department \\ University of Maribor \\ Faculty of Electrical Engineering and Computer Science, Smetanova 17, 2000 Maribor, Slovenia \\ Phone: +38622207180, Fax: +38622207272, e-mail: loris.somi@student.um.si, klemen.dezelak@um.si, \\ gorazd.stumberger@um.si
}

\begin{abstract}
Depends on amount of water per person, Slovenia is among the richest countries in Europe with almost four times the European average. The production of energy from water to wire is basically possible on the whole country area. This work deals with the area near to Ledava river, where the water accumulation system was built around 1970. From economical point of view, the aforementioned system is not really exploited. There are different possibilities, how to exploit the whole system, as with fishing industry, soaking industry or with convertion of hydro energy into electrical energy as part of renewable production units. The last mentioned is the part of presented research work in proposed paper.
\end{abstract}

\section{Key words}

Electrical system, accumulation small hydro power plant, lake, investment calculation.

\section{Introduction}

In paper the total analysis of present system for water accumulation is shown, where the solution for optimal exploitation of water energy by small hydro power plant is given. In that sense the whole aspects of an important and well preserved ecological zones, with a great diversity of animal and plant species are considered, firstly. Secondly the dimensions of accumulation systems and data about available and installed flow should be defined. Additionally some essential components of small hydro power plants, as penstock, power house and tailrace are dealt, as well. Penstock, that conveys water under pressure, can be made of steel, iron, plastics, concrete or wood. Power house contains most of the mechanical and electrical equipment and it is made of conventional building materials, whilst the tailrace carries the water from the turbine exit back to the river [1], [2]. Generally, such a system requires substantial initial capital investments and relatively low operating costs. Both of the aforementioned costs were evaluated inside the entireness economical analysis.

\section{Installation of object into the environment}

In case of some object installation into the environment an important attention should be given into areas where strict nature protection is presented. Those nature protection areas are:

a) landscape park (named "Goričko"),

b) NATURA 2000 (SPA and pSCI areas), (Fig. 1),

c) ecologically important areas (Fig. 2) and

d) area with strong natural value (Fig. 3).

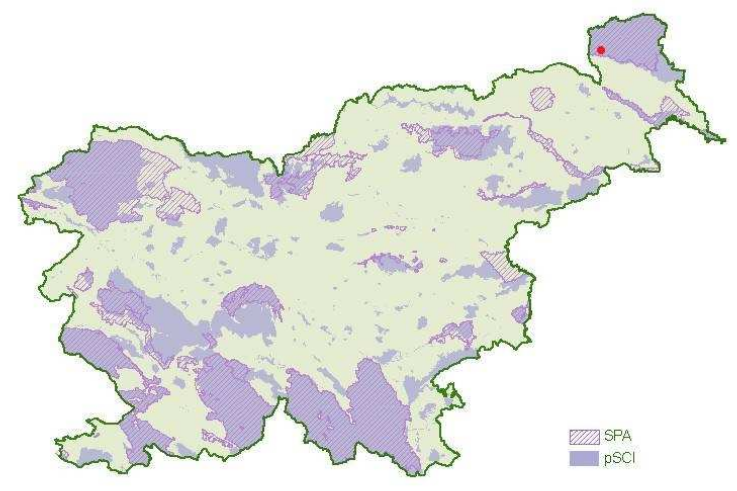

Fig. 1: Slovenia - NATURA 2000 areas.

The effect of the small hydro power plants on the environment is related to their development and varies according to the location and configuration of the project itself, since planning to construct a small hydro power plant at a less suitable location can trigger major effects on the environment. In case of constructing a small runof-river hydro power plant next to an already existing dam, in general, the effects on the environment are minimal. They are similar to those connected with enhancing the existing capacities. 


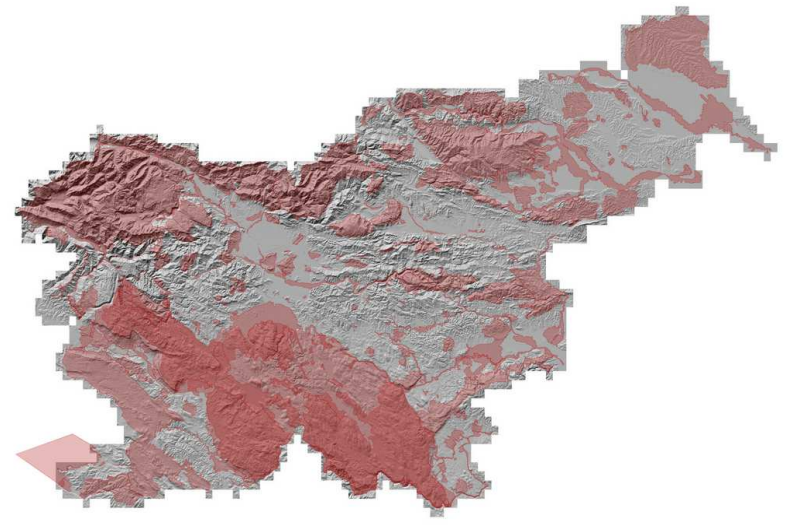

Fig. 2: Slovenia - ecologically important areas [3].

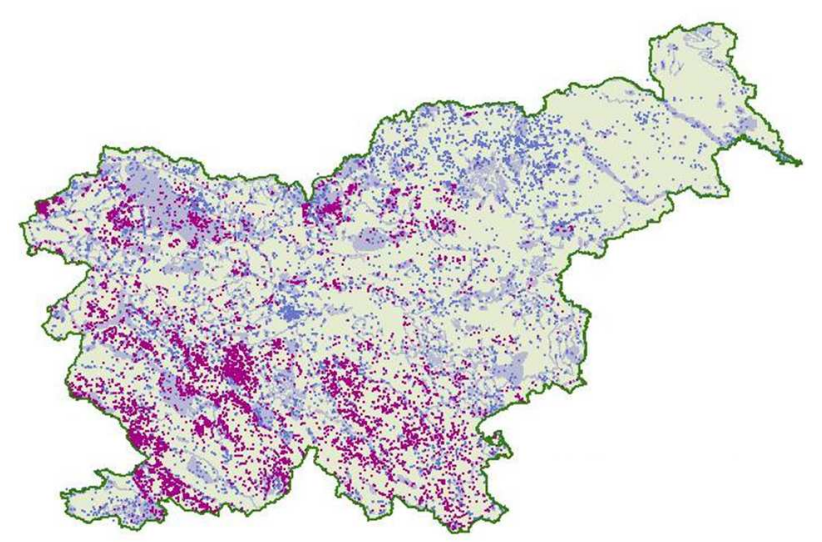

Fig. 3: Slovenia - area with strong natural value [4].

\section{Classification of hydro power plants in Slovenia}

In Slovenia the hydro power plants are classified in to four different groups (Tab. I), depends on the rated power of individual object.

Table I. - Classification of the hydro power plants in Slovenia

\begin{tabular}{|c|c|}
\hline & Rated power \\
\hline Micro & $<=50 \mathrm{~kW}$ \\
\hline Small & $50 \mathrm{~kW}<=1 \mathrm{MW}$ \\
\hline Middle & $1 \mathrm{MW}<=10 \mathrm{MW}$ \\
\hline Big & $>10 \mathrm{MW}$ \\
\hline
\end{tabular}

\section{Determination of design flow}

The power and produced energy of the hydro power plant are mainly dependent on the available flow [5] - [7]. In our case the average values of available flow for each month of year $Q$ are shown in Fig. 4. To calculate the delivered energy, instead of curve in Fig. 4, the curve shown in Fig. 5 should be considered in to the calculations. There, the values of monthly flows duration are defined. Apart from flow duration curve, the values of gross head, type of used turbine, design flow and generator efficiency are very important. The design flow is equal to $25 \%$ of flow value, so $0.85 \mathrm{~m}^{3} / \mathrm{s}$.

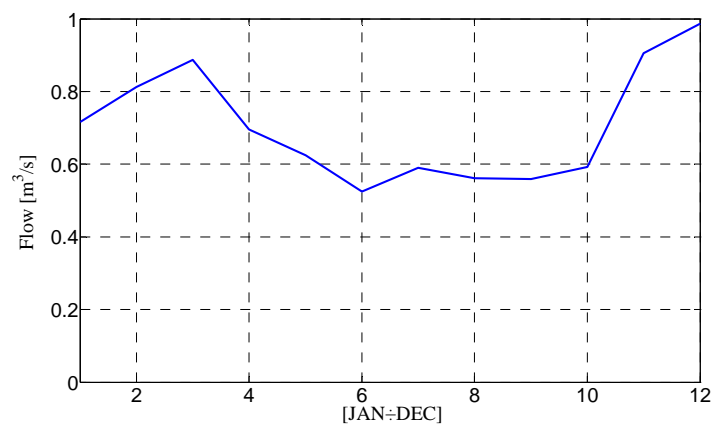

Fig. 4: Average values of available flow.

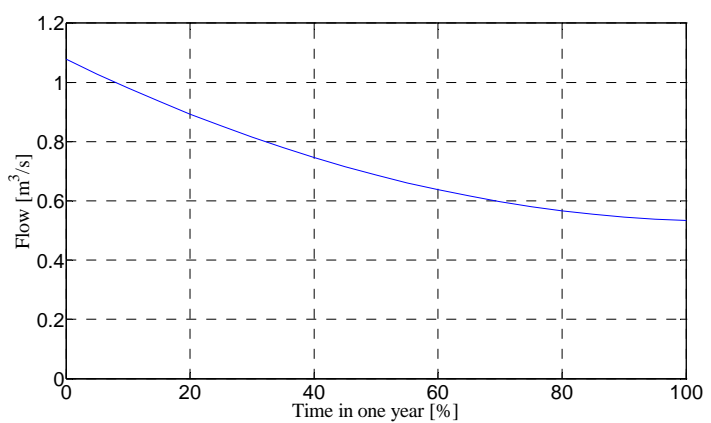

Fig. 5: Monthly flows duration curve.

\section{Intake of water}

As presented in Fig. 6, the small hydro power plant include some essential components as penstock, power house and tailrace. Penstock, that conveys water under pressure, can be made of steel, iron, plastics, concrete or wood. Power house contains most of the mechanical and electrical equipment and it is made of conventional building materials, whilst the tailrace carries the water from the turbine exit back to the river. In our case the water intake is performed by steel penstock with length and diameter $L_{\mathrm{C}}=75 \mathrm{~m}$ and $D_{\mathrm{C}}=0,8 \mathrm{~m}$.

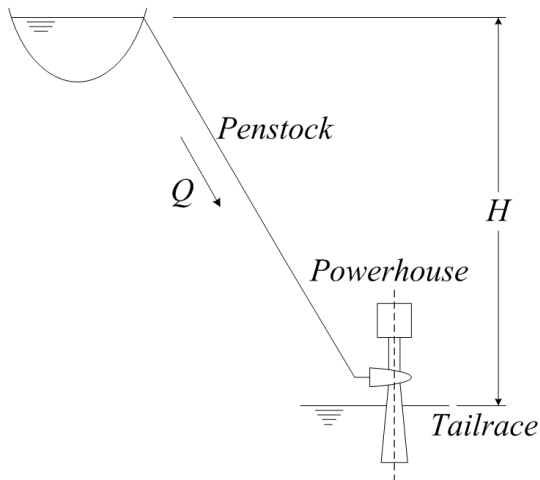

Fig. 6: Small hydro power plant system. 


\section{Determination of the net head}

The net head $H_{\mathrm{n}}$ (1) could be determined from gross head and hydraulic losses by two methods:

a) With the roughness factor $k_{\mathrm{h}}(2)$, that could be found in Tab. II.

$$
\begin{aligned}
& H_{\mathrm{n}}=H_{\mathrm{b}}-H_{\mathrm{i}}=H_{\mathrm{b}}-\lambda \cdot \frac{L_{\mathrm{C}}}{D_{\mathrm{C}}} \cdot \frac{v^{2}}{2} \cdot \frac{1}{g} \\
& \lambda=0,0055+0,15 \cdot\left(\frac{k_{\mathrm{h}}}{D_{\mathrm{C}} \cdot 1000}\right)^{0,3333}
\end{aligned}
$$

Table II. - Values of the roughness factor

\begin{tabular}{|c|c|}
\hline Steel & $0,15-0,50$ \\
\hline Iron & $0,25-1,00$ \\
\hline Concrete & $1,00-3,00$ \\
\hline Copper & 0,0015 \\
\hline PVC & 0,05 \\
\hline
\end{tabular}

In (1) the velocity of water is marked by $v(3)$.

$$
v=\frac{Q_{\text {inst }}}{S}=\frac{Q_{\text {inst }}}{\pi \cdot\left(\frac{D_{\mathrm{C}}}{2}\right)^{2}}
$$

Calculation of the net head by proposed method is shown below.

$$
\begin{gathered}
v=\frac{Q_{\text {inst }}}{\pi \cdot\left(\frac{D_{\mathrm{C}}}{2}\right)^{2}}=\frac{0,85}{\pi \cdot\left(\frac{0,80}{2}\right)^{2}}=1,691 \frac{\mathrm{m}}{\mathrm{s}} \\
\lambda=0,0055+0,15 \cdot\left(\frac{k_{\mathrm{h}}}{D_{\mathrm{C}} \cdot 1000}\right)^{0,3333}= \\
0,0055+0,15 \cdot\left(\frac{0,325}{0,80 \cdot 1000}\right)^{0,3333}=0,01661 \\
H_{\mathrm{n}}=H_{\mathrm{b}}-\lambda \cdot \frac{L_{\mathrm{C}}}{D_{\mathrm{C}}} \cdot \frac{v^{2}}{2} \cdot \frac{1}{g}= \\
7,30-0,01661 \cdot \frac{75}{0,80} \cdot \frac{1,691^{2}}{2} \cdot \frac{1}{9,81}=7,0731 \mathrm{~m}
\end{gathered}
$$

b) With the loss coefficient $k_{\mathrm{i}}(4)$, that could be found in Tab. III.

$$
H_{\mathrm{n}}=H_{\mathrm{b}}-H_{\mathrm{i}}=H_{\mathrm{b}}-\frac{v^{2} \cdot L_{\mathrm{C}}}{k_{\mathrm{i}}^{2} \cdot\left(\frac{D_{\mathrm{C}}}{4}\right)^{1,33}}
$$

Table III. - Values of the loss coefficient

\begin{tabular}{|c|c|}
\hline Concrete & 71 \\
\hline Steel & 83 \\
\hline Wood & 83 \\
\hline PVC & 120 \\
\hline
\end{tabular}

Calculation of the net head by proposed method is shown below.

$$
v=\frac{Q_{\text {inst }}}{\pi \cdot\left(\frac{D_{\mathrm{C}}}{2}\right)^{2}}=\frac{0,85}{\pi \cdot\left(\frac{0,80}{2}\right)^{2}}=1,691 \frac{\mathrm{m}}{\mathrm{s}}
$$

$$
\begin{gathered}
H_{\mathrm{n}}=H_{\mathrm{b}}-\frac{v^{2} \cdot L_{\mathrm{C}}}{k_{\mathrm{i}}^{2} \cdot\left(\frac{D_{\mathrm{C}}}{4}\right)^{1,33}}= \\
7,30-\frac{1,691^{2} \cdot 75}{83^{2} \cdot\left(\frac{0,80}{4}\right)^{1,33}}=7,0353 \mathrm{~m}
\end{gathered}
$$

\section{Selection of proper turbine}

Turbines are devices that convert the energy from falling water into rotating shaft power. Turbines used in examples of small or medium high heads (Fig. 7), are reactionary type. That type of turbine includes Francis and Kaplan turbines. In case of high heads (Fig. 7), the action turbines are used. The Pelton turbines, the Turgo turbines and the cross flow turbines are all examples of the action turbines. The proper turbine could be defined by values of design flow and head as is shown in Fig. 7. 


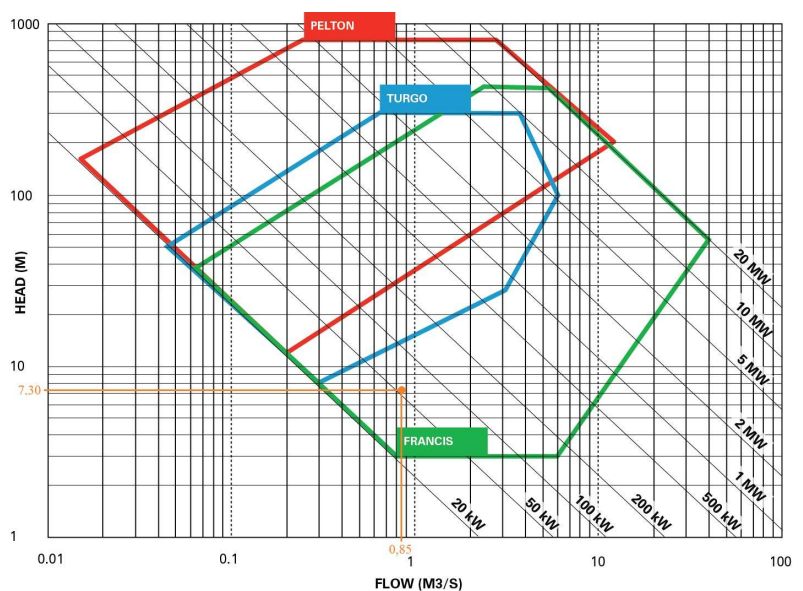

Fig. 7: The turbine selection.

\section{The power and efficiency of turbine}

Figs. 8 and 9 shows the available power and efficiency curves of chosen turbine. The rated power is equal to 51,3 $\mathrm{kW}$.

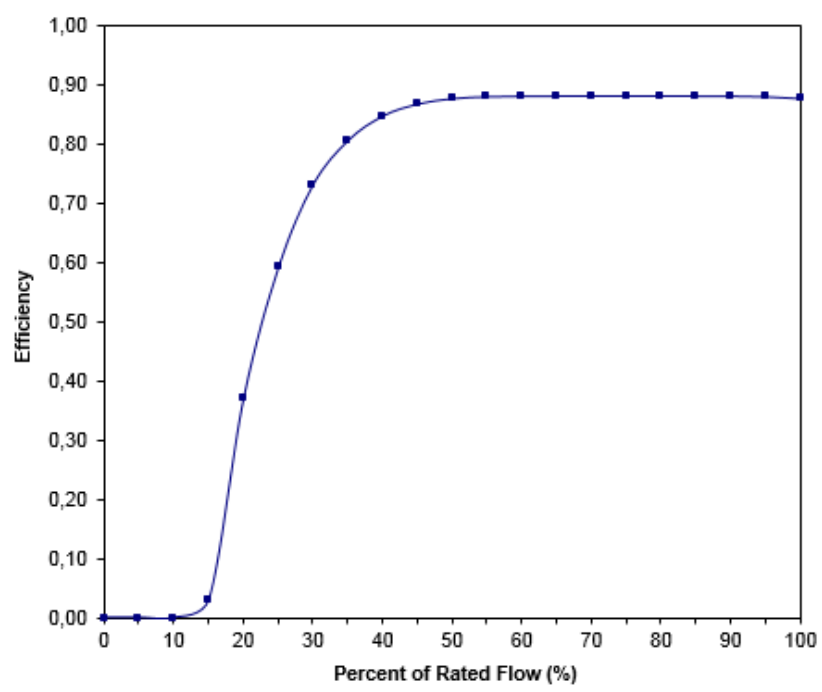

Fig. 8: The curve of turbine efficiency.

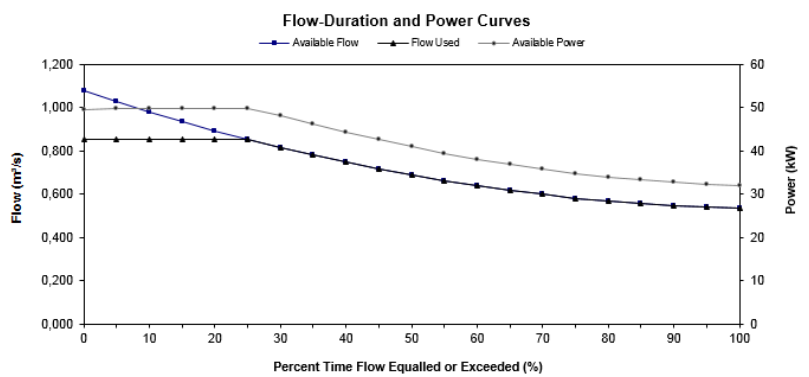

Fig. 9: The curve of available power.

\section{Initial costs}

Investment to the project depends on:

- penstock costs,

- turbine and generator costs,

- energy equipment installation costs,

- connection to the electrical grid costs,

- construction work costs,
- design documents costs, etc.

The value of total investment is approximately equal to $365.000,00 €$.

\section{Financial analysis}

Finally the cost of produced energy, credit ratio, credit interest rate, credit term, inflation and discount rate were considered, leading to result of cumulative cash flow presented in Fig. 10.

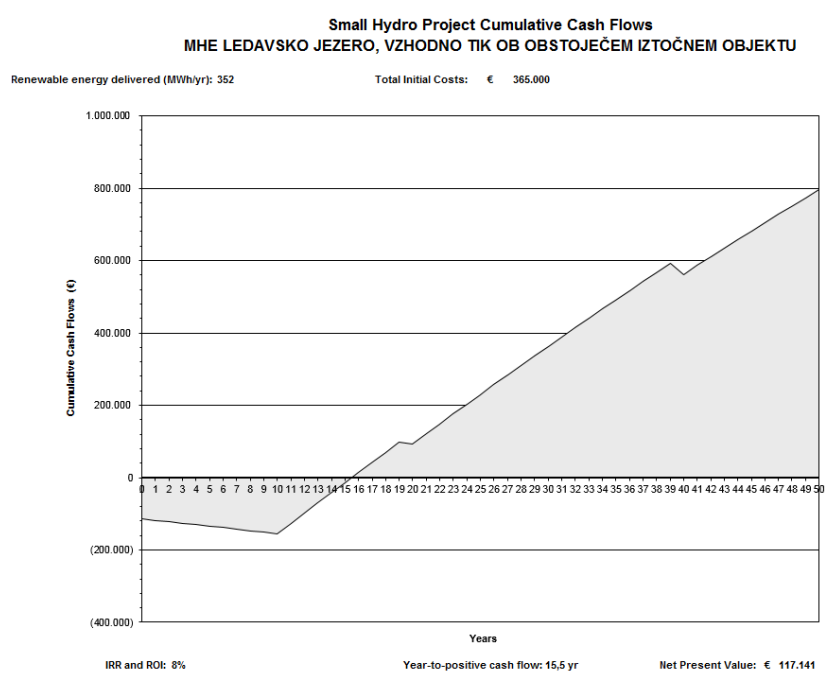

Fig. 10: Cumulative cash flow of the project.

\section{Conclusion}

This paper deals with an accumulation small hydro power plant on Ledavsko lake located in Slovenia. The possible project is built on an already existing environment or infrastructure, consisting of an embankment, a tower and a lake outflow. The choice of technical equipment, location and the planned operation regime, as well as the construction and investment cost of the small hydro power plant project are presented in the paper.

\section{References}

[1] C. Dragu, T. Sels, R. Belmans, "Small hydropower - state of the art and applications", Int. Conf. on Power Generation and Sustainable Development, AIM, 2001, Liege, Belgium

[2] P. R. Gingold, "The optimum size of small run-of-river plants", Water Power Dam Construct, 1983, pp. 35 - 39

[3]_http://geopedia.si/?params=L11410_T105_vL_b4_x48347 9_y102619_s9\#T105_L11410_x466839_y109019_s9_b4.

[4]_http://www.arso.gov.si/narava/naravne\%20vrednote/karta/ karta_naravne_vrednote.jpg, [11.07. 2014].

[5] B. Munson, D. Young, T. Okiishi, W. Huebsch, Fundamentals of fluid mechanics, 6th edition, 2010, Wiley

[6] C. Alonso-Tristán, D. González-Peña, M. Díez-Mediavilla, M. Rodríguez-Amigo, T. García-Calderón, "Small hydropower plants in Spain: A case study", Renewable and Sustainable Energy Reviews, 2011, Vol. 15, pp. 2729-2735.

[7] S. Mishra, S.K. Singal, D.K. Khatod, "Optimal installation of small hydropower plant-A review", Renewable and Sustainable Energy Reviews, 2011, Vol. 15, pp. 3862-3869. 